\title{
Erysipelas following a fracture: about a case
}

\begin{abstract}
Erysipelas on postoperative scar is a rare entity. In orthopedic traumatology, we have only the 3 cases reported in the work of Dhrif occurred during prosthetic implantation. We present through this article, the case of postoperative erysipelas on an osteosynthesis scar of a fracture of the lower quarter of the leg in a 58-year-old woman.
\end{abstract}

Volume 3 Issue I - 2019

\begin{abstract}
Abdelhafid El Marfi,' Mohamed El Idrissi,' El Ibrahimi Abdelhalim,' Abdelmajid El Mrini,'

Kaoutar Laamari, ${ }^{2}$ Fatima Zahra Mernissi ${ }^{2}$

'Department of Traumatology Orthopedy B4, University Hospital Hassan II Fez, Morocco

${ }^{2}$ Department of Dermatology, University Hospital Hassan II Fez, Morocco
\end{abstract}

Correspondence: Abdelhafid El Marfi, Department of Traumatology Orthopedy B4, University Hospital Hassan II Fez, Morocco, Tel 002126783398 79,

Email hafid_elmarfi@hotmail.fr

Received: January 04, 2018 | Published: January 28, 2019

\section{Introduction}

Erysipelas is an infectious disease of the dermis and subcutaneous tissue commonly caused by streptococci. ${ }^{1}$ It is a clinical form of acute cellulitis. ${ }^{2}$ Clinically, it is characterized by the acute onset of local signs of inflammation such as erythema, oedema, pain and heat. In its classic form, it is accompanied by systemic signs such as fever, chills and malaise and sometimes nausea and vomiting., Erysipelas can be serious but rarely fatal. It has a rapid and favorable response to antibacterial therapy. ${ }^{5,6}$ From an epidemiological point of view, we consider the existence of a portal of entry, lymphoedema and obesity as the main risk factors for occurrence. A post-operative scar entry portal after a fracture has been rarely described in the literature. We report in this work the case of a young patient who presented erysipelas of the leg on a surgical scar of an osteosynthesis for a closed fracture of the tibial pestle.

\section{Case report}

A 58-year-old woman presented in July 2017 to the Emergency Department at Hassan II University Hospital, Morocco, due to the rapid onset of fever, and a suspected skin infection. She had a previous medical history of a fracture of the lower quarter of the leg which was treated by a plate osteosynthesis (Figure 1) (Figure 2). She had a sharply demarcated, warm, and painful erythema on her leg surmounted by vesicles in places, purpuric by others, taking the operative scar (Figure 3). Vital parameters showed a temperature of $38.0^{\circ} \mathrm{C}$, respiratory rate of $18 \mathrm{breaths} / \mathrm{min}, \mathrm{O}_{2}$ saturation of $96 \%$ on room air, heart rate of $80 \mathrm{beats} / \mathrm{min}$, and blood pressure of $120 / 70 \mathrm{mmHg}$. Oral examination showed no signs of infection, and examination of lymph nodes was normal. Her laboratory results showed a white blood cell count of $22100 / \mathrm{mm}^{3}$, her CRP was $235 \mathrm{mg} / \mathrm{L}$. The radiological examination of the leg revealed a fracture in the process of consolidation without radiological signs of sepsis on the osteosynthesis material. She was clinically diagnosed with erysipelas she was treated with intravenous amoxicillin + clavulanic acid. Clinical and biological improvement was noted, resulting in the switch to the oral route on the fifth day of treatment. The patient received 21 days of antibiotic therapy. The evolution was marked by the complete disappearance of the cupboard with a decline of 1 year and a half without recurrence.

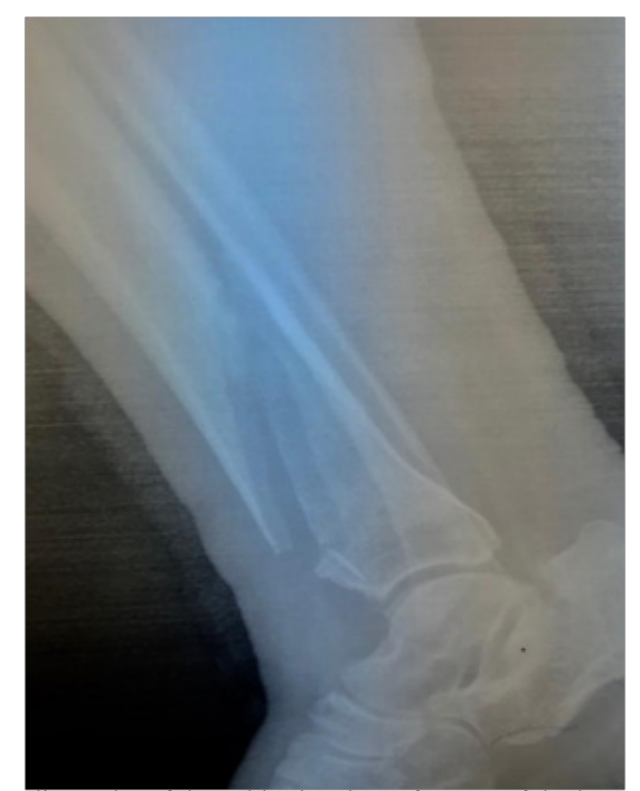

Figure 1 Radiography of the ankle showing a fracture of the lower quarter of the leg

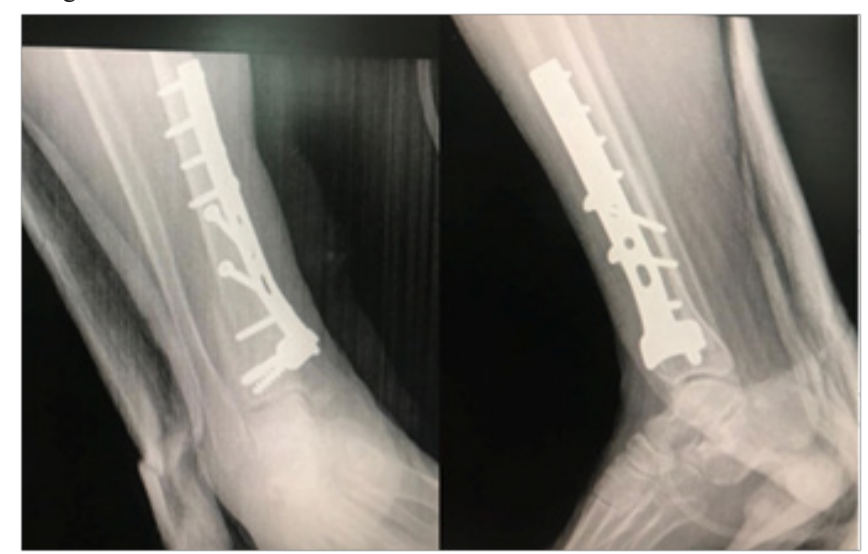

Figure 2 Control radiography after 3 months of postoperative surgery not showing signs of sepsis on material, with beginning of consolidation 


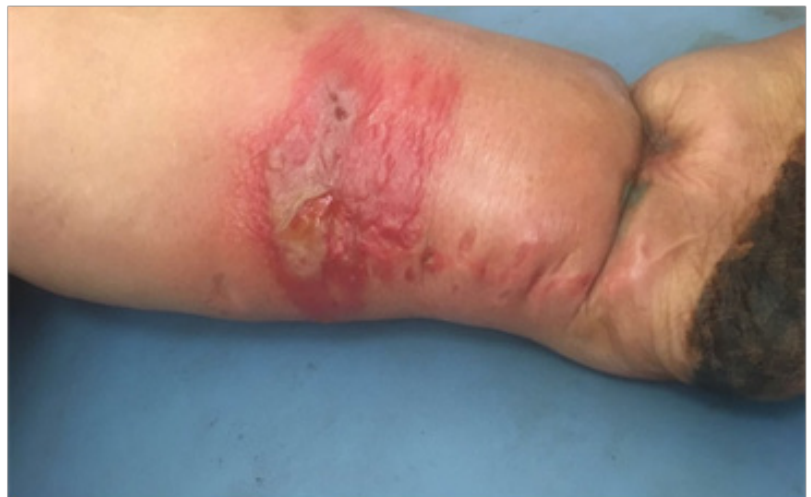

Figure 3 erythematous placards, oedematous at the level $2 / 3$ inferior of the right leg, surmounted by vesicles in places, purpuric by others, taking the operative scar

\section{Discussion}

Scar erysipelas is a rare entity. In traumatological and orthopedic surgery, we were able to find in the literature that the results of the work of Dhrif et al. ${ }^{7}$ having collected, on his retrospective study carried out between 1999 and 2003, 3 cases occurred in the suites of an osteoarticular prosthesis implantation at patients with a mean age of 61years, one of whom had chronic venous insufficiency.

It is assumed that the mechanism passes through lymphatic damage caused by surgery prosthetic. This local alteration would predispose to a certain degree of venous and lymphatic stasis. It is established that cellulites generally occur at the extremities where there are disorders of the venous circulation and lymphatic. ${ }^{8}$ The alteration of lymphatic drainage would be the origin retention of high molecular weight proteins in intercellular spaces and therefore edema rich in protein. If this lymphatic stasis persists, the proteins play a nutritious role for fibroblasts and induce therefore the formation of a fibrosis that would slow down itself the drainage capacity. ${ }^{9}$ By the way, the lymph undrained is an excellent growing medium for germs leading to cellulite. Inflammation participates also to the destruction of the lymphatic channels. ${ }^{10} \mathrm{~A}$ vicious circle then settles and explains the recidivism of erysipelas in these patients. Clinically, erysipelas on an operative scar has the same characteristics as erysipelas on healthy skin $^{8,11,12}$ It is a hot inflammatory erythematous inflammatory placard encompassing the cutaneous scar. Lymphadenopathy is present in about $30 \%$ of cases and pre-existing lymphoedema is reported with an incidence of $20 \%{ }^{11,13}$ At a distance from the first episode, most authors raise the major issue of residual lymphoedema and recurrence, which is observed in 6 to $57 \%$ of cases depending on the series and which occurs in patients at risk. In the literature, recurrence occurs in $12 \%$ of patients at 6 months, $28.5 \%$ at 2 years and $30 \%$ of cases at 3years in a context of persistent intertrigo inter-toe and especially of an infected surgical scar. ${ }^{14,15}$ In terms of prevention, the studies that have focused on this subject emphasize the major importance of the appropriate management of venous and lymphatic stasis, which is quite common among lower limb operated patients, first of all by lymphatic drainage physiotherapy. Manual that can be started in the immediate after operative suites, then by the wearing of compression stockings alternately. ${ }^{16,17}$

\section{Acknowledgments}

None.

\section{Conflicts of interest}

Authors declare that there is no conflicts of interest.

\section{References}

1. Grosshans EM. The red face: erysipelas. Clin Dermatol. 1993;11(2):307-313.

2. Bernard P, Bedane C, Mounier M, et al. Bacterial Dermohypodermatitis of the adult. Incidence and place of streptococcal etiology. Ann Dermato Venereol. 1995;122(8):495-500.

3. Bisno AL, Stevens DL. Streptococcal infections of skin and soft tissues. N Engl J Med. 1996;334(4):240-245.

4. Bonnetblanc JM, Bedane C. Erysipelas: recognition and management Am J Clin Dermatol. 2003;4(3):157-163.

5. Crickx B. Erysipèle: évolution médicale sous traitement: Complications Ann Dermatol Venereol. 2001;30(4):359-364.

6. Jorup-Ronstrom C. Epidemiological, bacteriological and complicating features of erysipelas. Scand J Infect Dis. 1986;18(6):519-524.

7. Dhrif AS, El Euch D, Ben Tekaya N, et al. [Erysipelas after osteoarticular prosthesis]. Med Mal Infect. 2005;35(9):463-465.

8. Baddour LM, Bisno AL. Non-group A beta-haemolytique streptococcal cellulitis: association with venous and lymphatic compromise. Am J Med. 1985;79(2):155-159.

9. Thomas V, Bourgault Villada I, Julien D, et al. Érysipèle après prothèse articulaire: signe d'alarme d'infection de la prothèse. Ann Dermatol Venereol. 1995;122(Supp):68-69.

10. Herpertz U. Erisipelas and lymphedema. Fortschr Med 1998;116(12):36-40.

11. Dupuy A. Épidémiologie descriptive et connaissance des facteurs de risque de l'érysipèle. Ann Dermatol Venereol. 2001;128(3 Pt 2):312316

12. Karakas M, Baba M, Aksungur VL, et al. Manifestation of cellulitis after saphenous venectomy for coronary bypass surgery. $J$ Eur Acad Dermatol Venereol. 2002;16(5):438-440.

13. Vaillant L. Complications infectieuses des lymphoedèmes. Rev Méd Int 2002;23(Sup 3):403s-407s.

14. Cricks B. Erysipèle: données épidémiologiques, cliniques et thérapeutiques. Ann Dermato Vénéréol. 1991;118:11-16.

15. Conférence de consensus. Érysipèle et fasciite nécrosante: prise en charge. Ann Dermatol Venereol. 2001;128:463-482.

16. Johnsson $\mathrm{K}$, Albertsson $\mathrm{M}$, Ingvar $\mathrm{C}$, et al. Effects of compression bandaging with or without manual lymph drainage treatment in patients with postoperative lymphedema. Lymphology. 1999;32(3):103-110.

17. Ferrandez JC, Serge T, Jean-Yves B. Drainage manuel Recommandations pour une pratique basée sur les faits. Kinésithér Rev. 2011;11(115-116):41-47. 